\title{
Second wave of COVID-19 in Brazil: younger at higher risk
}

\author{
Fernanda Sumika Hojo de Souza ${ }^{1}$ - Natália Satchiko Hojo-Souza ${ }^{2} \cdot$ Cristiano Maciel da Silva $^{3}$. \\ Daniel Ludovico Guidoni ${ }^{1}$
}

Received: 1 April 2021 / Accepted: 8 April 2021 / Published online: 21 April 2021

(c) Springer Nature B.V. 2021

The Brazilian Amazon region was severely affected by the COVID-19 epidemic, which started in March 2020. After a cases and deaths peak in May 2020, a study conducted by Buss et al [1] indicated that in October 2020 more than $70 \%$ of the population of Manaus (capital of the Amazonas State) had been infected with SARS-CoV-2. Socioeconomic factors may have been the cause of this extensive transmission in the region. Theoretically, this percentage of the infected population could provide protection mediated by herd immunity. In fact, although there has been relaxation of individual protective measures and social distancing, hospitalizations due to COVID-19 remained stable and lower between May and November 2020 in Manaus [2]. Importantly, some factors such as antibody levels reduction against the virus and the emergence of new variants could contribute to new pandemic waves ocurrence [1]. In November 2020, a second wave reached the Amazonas State, more likely by the emergence of a new virus variant, named P.1, detected in Manaus on Jan 12, 2021 [2]. This variant, classified as a new lineage, is $\approx 2.5$ times more transmissible than that of the first wave [3], being classified as a "variant of concern" (VOC). Regarding the lethality, there are still not enough studies.

In the first wave, likewise different countries, COVID19 mainly affected elderly Brazilians with comorbidities [4]. On the other hand, empirical evidence has indicated a significant increase in the number of infected young adults (20-59 years old), admitted to the Intensive Care Unit (ICU), need for Invasive Mechanical Ventilation (IMV) as well as an increased mortality in this age group during the second

Fernanda Sumika Hojo de Souza

fsumika@ufsj.edu.br

1 Department of Computer Science, Federal University of São João del-Rei, São João del-Rei, MG, Brazil

2 Laboratory of Immunopathology, Fundação Oswaldo Cruz Minas, Belo Horizonte, MG, Brazil

3 Department of Technology, Federal University of São João del-Rei, Ouro Branco, MG, Brazil wave. The increased number of hospitalization cases may reflect the number of total cases due to the greater infectivity of the P.1 variant, which already showed a frequency of $91 \%$ in the Amazonas' samples that were sequenced in January, 2021 [5].

Amazonas State has experienced early epidemic peaks, compared to other regions of the country. According to Buss et al, Manaus represents a "sentinel" population by indicating events that can occur with SARS-CoV-2 dissemination without largely mitigation [1]. Publicly available data in the Brazilian Ministry of Health database (SIVEP-Gripe) [6] shows that during the second wave there is an increase in the total number of hospitalizations, deaths, ICU admission and IMV need by COVID-19 patients from Amazonas when compared to the first wave. In addition, we can also notice a significant increase in ICU admission, IMV need and mortality of 20-59 years old patients (Fig. 1a). Such incidence does not appear in data from all over Brazil in the same period, as shown in the Fig. 1(b).

These observations demonstrate that SARS-CoV-2 infection can also be lethal for young adults. Perhaps, this phenomenon is a Brazilian demography reflex, a country with a younger population, or possibly due to social differences that prevent poor young people from keeping social distance, increasing the chances of contagion. Importantly, after a year of pandemic, young people are also relaxing for nonpharmaceutical interventions (NPIs) to contain COVID-19. The early loss of young people is an unacceptable fact for any country that cares about future generations.

Vaccination in Brazil started by prioritizing the elderly population and health professionals. However, due to the worsening of the disease in the population of young adults pointed out by the data, it is necessary to implement urgent measures to protect this age group, as it constitutes the workforce that moves the country.

In this second wave, Brazil is experiencing an unprecedented economic, social and health crisis. With crowded ICUs and records reaching almost 3000 daily deaths [7], there is an imminent threat of a lack of hospital beds and 
$\mathbf{a}$

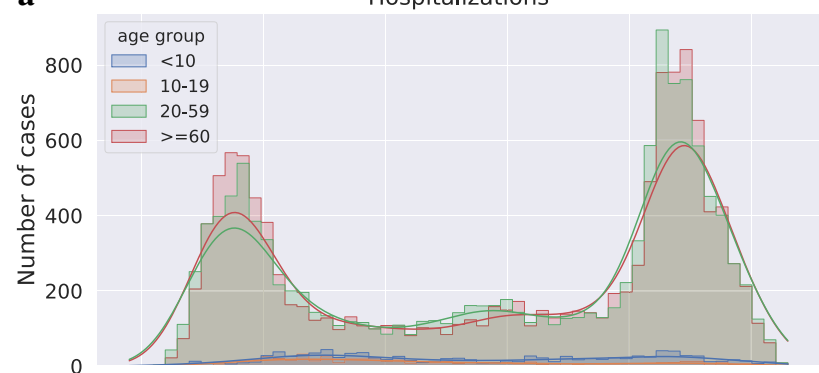

ICU

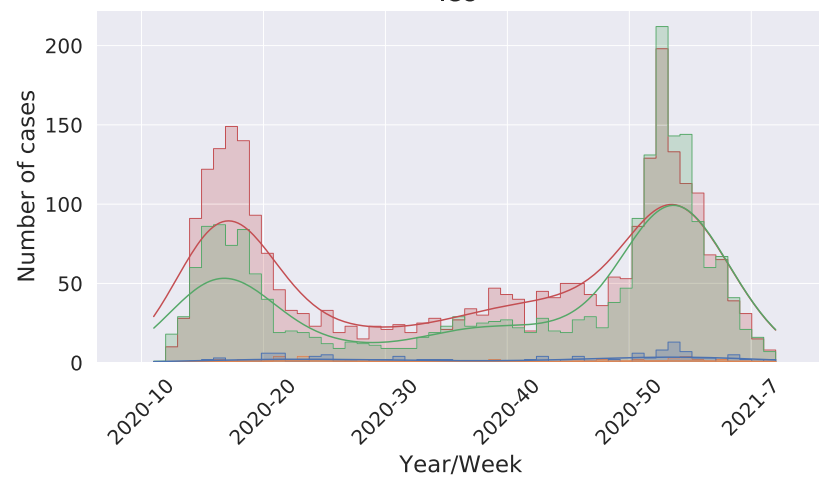

b

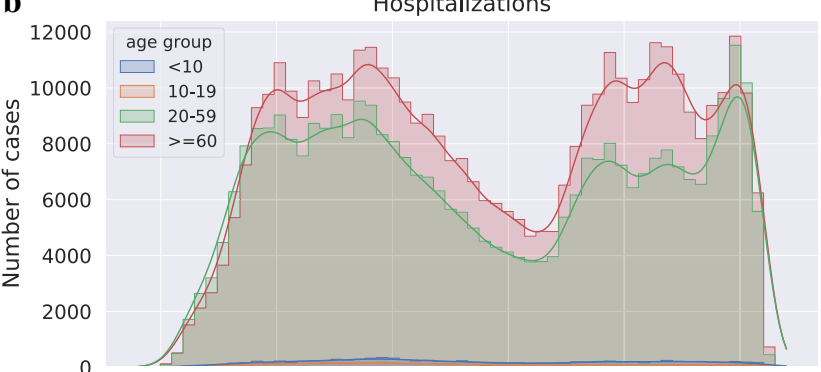

ICU

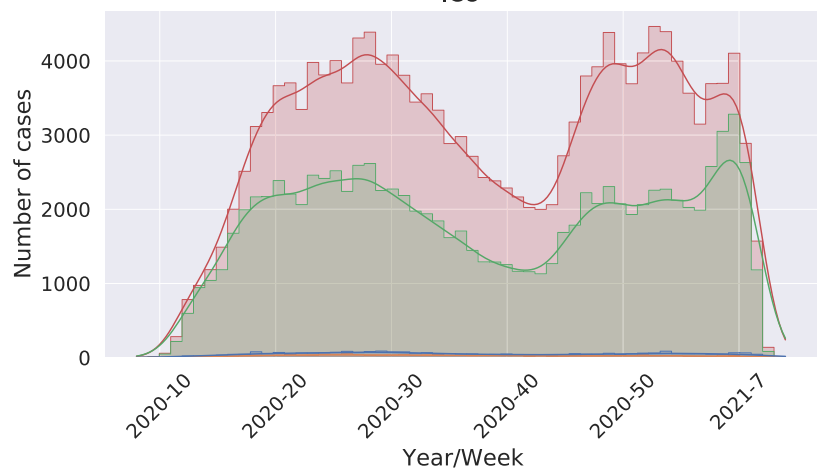

Fig. 1 COVID-19 hospitalizations, in-patient deaths, ICU admission and IMV need in Amazonas and Brazil, 2020-21. The number of cases for each epidemiological week (first symptoms) was extracted from SIVEP-Gripe database from the Brazilian Ministry of Health. The data were stratified by age group in order to show the highest
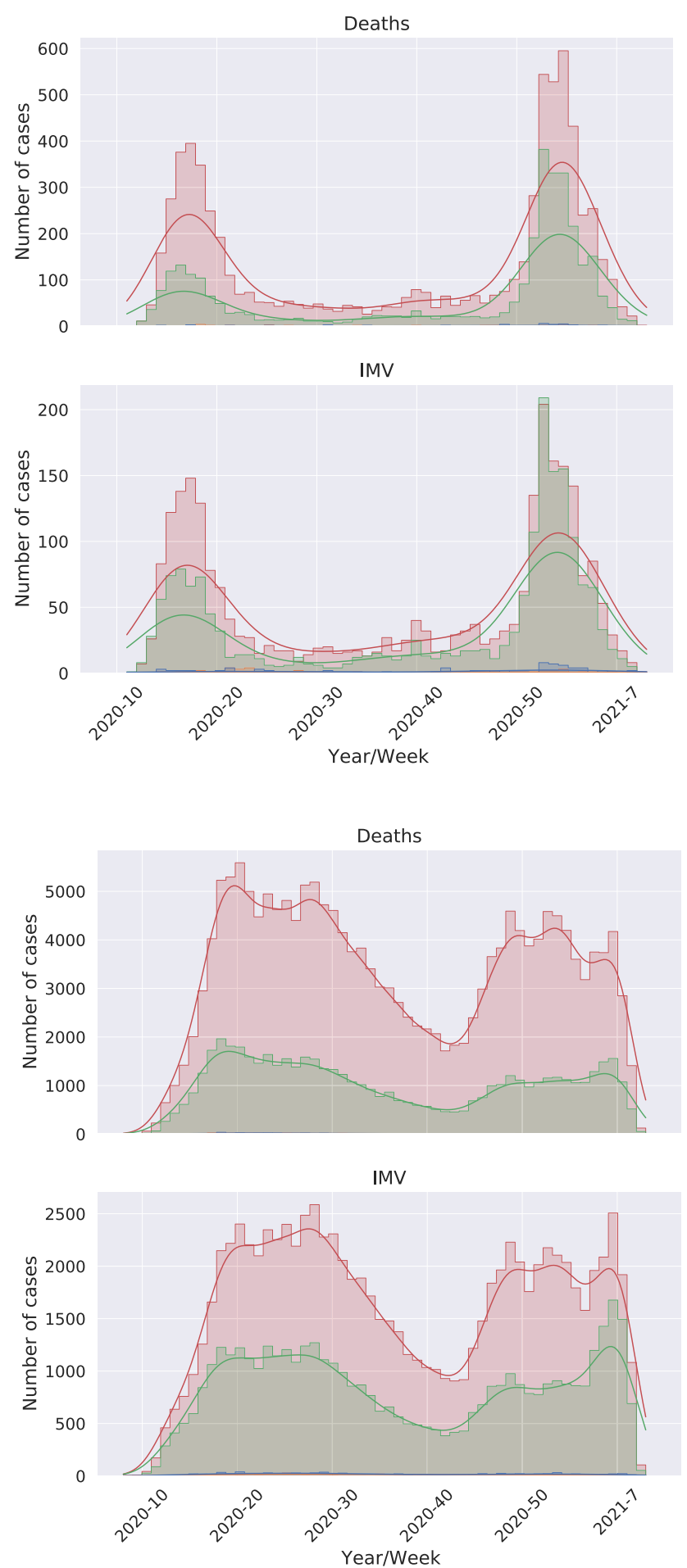

incidence of young adults being affected by the virus, leading to an increase in ICU admission and invasive mechanical ventilation need during the second wave of COVID-19 in the state of Amazonas (a) and the rest of Brazil (b) 
basic supplies supporting and providing the proper treatment to COVID-19 patients, indicating that the country is heading towards the most drastic sanitary collapse of its history. The low availability of vaccines and the slow vaccination rate for a population of more than 200 million Brazilians tend to prolong and aggravate the current situation, maybe even leading to new SARS-CoV-2 variants, which can compromise the effectiveness of the actual vaccines, and increase the crisis worldwide.

At this very moment, the second wave in Brazil is moving from regional to national, and the situation in Amazonas is calming down. Such may indicate that the Amazon region, including the capital Manaus, may represent the "sentinel" population, as suggested by Buss et al [1]. The fact is that the P.1 variant that emerged in Amazonas was not successfully contained, and now it is being detected in samples from patients in several Brazilian States [8]. This severe pandemic situation has caused a widespread fear that Brazil could become a global threat if more drastic and effective measures are not taken to contain the virus until a significant share of the population has been vaccinated.

Funding The authors received no funding from any Institution or Foundation for this study.

Data availability The data used in this work is publicly available [6].

\section{Declarations}

Conflict of interest The authors declare that they have no conflict of interest.

Ethical approval This study did not directly involve patients and does not require approval by an ethics committee.

\section{References}

1. Buss LF, Prete CA, Abrahim CMM, Mendrone A, Salomon T, de Almeida-Neto C, et al. Three-quarters attack rate of SARS-CoV-2 in the Brazilian Amazon during a largely unmitigated epidemic. Science. 2021;371(6526):288-92.

2. Sabino EC, Buss LF, Carvalho MPS, Prete CA, Crispim MAE, Fraiji NA, et al. Resurgence of COVID-19 in Manaus, Brazil, despite high seroprevalence. The Lancet. 2021;397(10273):452-5.

3. Coutinho RM, Marquitti FMD, Ferreira LS, Borges ME, da Silva RLP, Canton O, et al. Model-based estimation of transmissibility and reinfection of SARS-CoV-2 P.1 variant. medRxiv. 2021. Available from: https://www.medrxiv.org/content/early/2021/03/ 09/2021.03.03.21252706.

4. de Souza FSH, Hojo-Souza NS, Batista BDdO, da Silva CM, Guidoni DL. On the analysis of mortality risk factors for hospitalized COVID-19 patients: A data-driven study using the major Brazilian database. PLOS ONE. 2021;16(3):1-21.

5. Naveca F, Costa C. Caracterização genética do SARS-CoV-2 circulante no Estado do Amazonas. Nota Técnica Conjunta No 09/Fiocruz/ILMD E FVS-AM; 2021. Published online Jan 28. [Accessed March 15, 2021]. Available from: https://amazonia. fiocruz.br/wp-content/uploads/2021/01/NOTA-TE\%CC\%81CNI CA-CONJUNTA-N\% C2\%BA-09.2021.FVS-AM-X-ILMD. FICRUZ-AM-28.01.2021.pdf.

6. Brasil. Ministério da Saúde. Sistema de Informação de Vigilância Epidemiológica da Gripe, SIVEP-Gripe; 2021. [Accessed March 17, 2021]. Available from: https://opendatasus.saude.gov.br/.

7. Brasil. Ministério da Saúde. Painel Coronavírus; 2021. [Accessed March 18, 2021]. Available from: https://covid.saude.gov.br/.

8. Observatório Covid-19 Fiocruz. Fiocruz detecta mutação associada a variantes de preocupação do Sars-Cov- 2 em diversos estados do país. Observatório Covid-19 Fiocruz: Informação para ação; 2021. Published online March, 4. [Accessed March 15, 2021]. Available from: https://portal.fiocruz.br/sites/portal.fiocruz.br/ files/documentos/comunicado_variantes_de_preocupacao_fiocr uz_2_2021-03-04.pdf.

Publisher's Note Springer Nature remains neutral with regard to jurisdictional claims in published maps and institutional affiliations. 